\section{Medios de Comunicación y Procesos Constituyentes: El caso de El Mercurio en Chile $^{*}$}

Mass Media and Constituent Processes: The case of El Mercurio in Chile

\author{
Alberto Coddou-McManus* \\ José Manuel Ferreiro-Gómez
}

\section{Resumen}

Chile se encuentra actualmente en medio de un proceso constituyente. A los movimientos por una Asamblea Constituyente (AC) que

Agradecemos especialmente los comentarios que a borradores anteriores han hecho Javier Castillo y Carla Moscoso, así como los evaluadores. Cualquier error en este texto es nuestra responsabilidad.

** Candidato a doctor en Derecho, University College of London; Master en Derecho (LLM), New York University; Licenciado en Ciencias Jurídicas y Sociales, Universidad de Chile. Profesor de Derecho Constitucional e Investigador del Centro de Derechos Humanos, Universidad Diego Portales. E-mail: acoddoumc@ gmail.com.

*** Candidato a doctor en Lingüística y Master en Estudios de Discurso, Lancaster University; licenciado en Sociología, Universidad de Chile. E-mail: josemanuelferreiro@yahoo.es. alcanzaron notoriedad durante la elección presidencial de 2014, se sumó la decisión presidencial de iniciar el proceso de elaboración de una nueva constitución que cuente con la participación de la ciudadanía. En este contexto, resulta de vital importancia el papel que los medios de comunicación tendrán en difundir la información sobre el proceso constituyente y en facilitar el debate público sobre la nueva constitución. Este artículo pretende aportar a la discusión sobre el rol de los medios de comunicación en un proceso constituyente, tomando como ejemplo el caso de El Mercurio. Con herramientas de lingüística de corpus, se examinarán los patrones ideológico-discursivos en la cobertura que ha hecho el diario El Mercurio- históricamente vinculado a la elite sobre el proceso constituyente en curso.

Palabras claves: procesos constituyentes, medios de comunicación, lingüística de corpus, democracia, El Mercurio.

\begin{abstract}
Currently, Chile is in the middle of a constituent process. Together with the movements advocating for a Constituent assembly (AC), which obtained notoriety during the 2014 presidential elections, there was a presidential decision to start a process for drafting a new Constitution with participation of the citizens. In this context, the role of mass media in spreading the information about the constituent process is crucial in facilitating the public debate about a new Constitution. This paper aims to contribute to the discussion about the role of mass media in a constituent process, taking the newspaper El Mercurio as a case study. By using corpus
\end{abstract}


linguistics tools, we examine the discursiveideological patterns of the ongoing constituent process in the coverage of El Mercurio historically linked with the elite.

Key words: constituent processes, mass media, corpus linguistics, democracy, El Mercurio.

\section{Introducción}

Chile ha iniciado un proceso constituyente único en su historia, convocando a la ciudadanía a participar directamente en la creación de las bases de un proyecto de nueva constitución, cuyo mecanismo de creación deberá ser definido por el próximo Congreso Nacional, a ser elegido en 2017. Cuando el Estado llama a la ciudadanía a tomarse en serio la idea de soberanía popular, el régimen jurídico puede garantizar que la convocatoria sea abierta, transparente, y que no tenga una agenda escondida de cooptación de líderes, movimientos sociales, o de la sociedad civil en general. Sin embargo, el Estado no puede controlar la naturaleza política del proceso constituyente, necesariamente abierta e incierta. De ahí que el rol de la ciudadanía, y de la sociedad civil organizada, sean vitales para el éxito del proceso constituyente ${ }^{1}$. $Y$ con ello nos referimos a actores individuales y colectivos, con diferentes capacidades de influencia y

\footnotetext{
Para una reciente auditoría sobre la democracia chilena, la debilidad estructural de la sociedad civil en temas de participación se expresa en diversos problemas: descenso sostenido de la participación política formal, especialmente entre los más jóvenes y los sectores más pobres; bajos niveles de asociatividad (bajo el promedio regional de participación en organizaciones sociales y comunitarias); escasos espacios y mecanismos de participación ciudadana en la esfera pública - estatal; debilidad estructural de las organizaciones de la sociedad civil como intermediarios entre la ciudadanía y el Estado; por último, una opinión generalizada de que los ciudadanos tienen "pocas oportunidades para participar, ser escuchados y que su opinión sea tomada en cuenta en los distintos niveles de gobierno" (PNUD 2014: 41-42).
}

configuración de la esfera pública. En este trabajo, nos centraremos en el rol de los medios de comunicación, como actores relevantes que articulan formas de participación de la sociedad civil en el proceso constituyente.

En el marco de ese proceso, se han generado muchos cuestionamientos a las primeras etapas del mismo, denominadas instancias de educación cívica y constitucional, y de diálogos ciudadanos. Ello ha generado un debate acerca del rol del gobierno de Michelle Bachelet, legitimado democráticamente para promover y cumplir las promesas de su campaña contenidas en su programa político, entre las que se cuenta "una nueva constitución". El rol protagónico que adquiere el Estado y su aparataje institucional, cuyas riendas actualmente están en manos de una coalición política que busca re-legitimar sus ideas después de varias décadas en el poder, tiende a minimizar el rol que le puede corresponder a entes privados, en especial aquellos que cumplen funciones relevantes para estas primeras etapas del proceso constituyente.

En concreto, nos referimos a actores privados que gozan de poderes comunicacionales con capacidad de influir en la agenda pública, y que articulan y configuran el modo en que se discute acerca de los asuntos públicos². En otras palabras, se trata de los principales actores que

\footnotetext{
Aparte del poder político, social y económico, Habermas analiza el poder de los medios de comunicación: "El poder de los medios está basado en la tecnología de los medios de masas. Aquellos que trabajan en los sectores políticamente relevantes del sistema de medios (ej., periodistas, columnistas, editores, directores, productores, y publicadores) no pueden no ejercer poder, ya que seleccionan y procesan el contenido políticamente relevante y por tanto intervienen tanto en las formación de opiniones públicas como en la distribución de los intereses influyentes. La utilización del poder de los medios se manifiesta en la elección de información y el formato, en las formas y el estilo de los programas, y en los efectos de su difusión" (2006: 419).
} 
pueden influir en la esfera pública, aquellos que en el contexto de sociedades diversas y que observan patrones avanzados de consumo, son capaces de articular la dirección que pueden tomar los poderes que administran los asuntos públicos (poder político). Entre estos actores, y sobre todo en estas primeras etapas del proceso constituyente, la prensa adquiere un rol casi tan protagónico como el que juega el Estado.

Los desafíos son aún mayores si pensamos que Chile tiene uno de los mercados de medios más concentrados a nivel mundial: de acuerdo a un reciente estudio comparado, por ejemplo, que mide la cantidad de voces en 31 países desarrollados y en desarrollo (es decir, entidades que tengan más del $1 \%$ del mercado en alguna de las 13 industrias de medios), Chile tiene los peores números, muy por debajo del promedio mundial (Noam 2015). Como destaca un reciente informe del Programa de Naciones Unidas para el desarrollo humano, "en Chile se advierte efectivamente una creciente concentración de medios tanto en prensa escrita como en radio. A su vez, importantes grupos económicos del país son propietarios de distintos medios y concentran gran parte de la audiencia y de la recaudación publicitaria, lo que dificulta que se genere nueva competencia" (PNUD 2014: 134) ${ }^{3}$.

En este trabajo, analizaremos el rol que puede corresponder a la prensa escrita en el proceso constituyente. Para ello, ocuparemos

Ello transforma el problema de la concentración en un asunto de interés público, y promueve un rol activo del Estado en garantizar la pluralidad de medios exigida por la protección de la libertad de expresión y opinión (véase, por ejemplo, la recomendación n34 del Comité de Derechos Humanos de Naciones Unidas). Hasta el momento, en Chile no se ha legislado específicamente sobre la concentración de medios, y las iniciativas dirigidas a ello, contenidas originalmente en la actual Ley de Prensa (por ejemplo, aquellas contenidas en el artículo 43 del proyecto de ley original), fueron cuestionadas por el Tribunal Constitucional (Rol 226-1995). dos teorías normativas de la democracia que han buscado explicar la mayor legitimidad democrática que deben tener los denominados momentos constitucionales para servir como espacios de creación constituyente. La estructura es la siguiente: después de una breve descripción de las teorías dualista y deliberativa de la democracia, se realizará una introducción al rol de los medios de comunicación en procesos constituyentes y el estado actual de la prensa escrita chilena y la libertad de expresión. Para finalizar, se realizará un análisis de discurso asistido por corpus, para mostrar las construcciones de la prensa escrita sobre el actual proceso constituyente chileno.

\section{Proceso constituyente y democracia dualista/deliberativa}

Un proceso constituyente, en términos ideales, materializa el ideal clásico de la soberanía popular. Se inicia, de manera difusa, con ideas políticas que buscan constituirse en aquellos principios que unen y definen la identidad política de una comunidad. Gradualmente, el proceso constituyente adquiere formas institucionales, y va adoptando el carácter de un proceso reglado que, nuevamente en términos ideales, debe tener la flexibilidad suficiente para ir adaptándose y materializando los ideales originales que se postularon como constitutivos en un comienzo 4 .
La práctica constituyente nos ofrece diversos ejemplos: desde casos en que las nuevas constituciones se crean de acuerdo a las reglas constitucionales vigentes, o que estas contienen mecanismos de reemplazo total, hasta casos de cuestionamientos a la institucionalidad vigente que terminan en nuevas constituciones. 
Además de estos grandes ideales políticos, que van entremezclados con las experiencias subjetivas y biográficas de los participantes, un proceso constituyente requiere de acuerdos generales en torno al procedimiento, es decir, una idea general acerca de las reglas de acuerdo a las cuales ese proceso desembocará en un cierto resultado, acuerdos que requieren un trasfondo compartido en el que la opinión pública juega un rol fundamental. En tanto manifestación del ideal democrático del autogobierno colectivo, la idea de proceso constituyente se puede entender en el marco de una concepción deliberativa y dualista de la democracia, entre otras posibilidades.

\subsection{Democracia deliberativa}

A diferencia de una concepción liberal de la democracia, que pone el acento en la protección de libertades individuales, y de una concepción republicana, que enfatiza los vínculos colectivos que surgen a partir (o con ocasión) del ejercicio de la auto-determinación colectiva, la concepción deliberativa de la democracia está centrada en la capacidad que tienen los procedimientos racionales de toma de decisiones de llegar a resultados óptimos para la solución de problemas colectivos. La conexión entre estas teorías normativas de la democracia y sus diferentes metodologías empíricas para evaluar la práctica supone perspectivas particulares. Para Habermas, el

paradigma deliberativo ofrece como su principal punto de referencia empírico un proceso democrático que es capaz de generar legitimidad a través de procedimientos de opinión y formación de voluntad que garantizan (a) publicidad y transparencia para el proceso deliberativo, (b) inclusión e igual oportunidad para la participación en el mismo, y (c) una presunción justificada de obtener resultados razonables (principalmente considerando el impacto de los argumentos en los cambios racionales en las preferencias). Más aún, la presunción de resultados razonables descansa en la premisa de que los discursos institucionalizados movilizan las demandas y temas considerados relevantes, promueven la evaluación crítica de las contribuciones, y llevan a reacciones racionalmente motivadas que pueden terminar en un 'sí' o un 'no' (2006: 413)

En la actualidad, existe una gran cantidad de estudios empíricos que buscan medir la capacidad de la comunicación y deliberación políticas como instancias de aprendizaje cooperativo y de solución de problemas colectivos (Neblo 2005; Fishkin y Luskin 2005; Heath 2001). Estos estudios apoyan la idea básica de que las democracias deben incorporar mecanismos de deliberación, asumiendo que las preferencias políticas no vienen dadas o fijas, y que estas pueden cambiar con el tiempo una vez que se accede a más y mejor información, o en que el intercambio de ideas permite una delimitación más clara del asunto a resolver. De algún modo, la idea de la democracia deliberativa se plantea como una crítica a las democracias meramente electorales y a aquellas que adoptan modelos de elección racional para la solución de problemas de acción colectiva (Habermas 2006: 414).

Si bien estos estudios han considerado casos de investigación extremadamente acotados, cuyas condiciones distan de las prácticas de comunicación política mediada en sociedades contemporáneas (en donde observamos una falta de deliberación ciudadana cara a cara' y en que los términos y condiciones de la discusión no son igualitarios ni recíprocos), los teóricos de la democracia deliberativa han buscado proyectar estos resultados para fortalecer los procesos de deliberación política (Habermas 2006). Hoy en día se ha llegado a hablar del giro sistémico en las teorías de la deliberación: del paso de estudios circunscritos a instancias 
decisionales particulares, a investigaciones que buscan evaluar cómo estas instancias se integran en un verdadero sistema democrático (Mansbridge et al 2012).

La idea de una democracia deliberativa, en el marco de procesos constituyentes, reconoce la existencia de ciertos puntos de partida, tanto a nivel individual como colectivo. Los ciudadanos, en nuestras diversas experiencias de vida, hemos desarrollado ideas acerca lo bueno y lo justo, de las relaciones sociales, y del entorno en que vivimos. Por supuesto, además, hemos desarrollado ciertas preferencias en torno a la solución de los problemas de convivencia e interacción de nuestras comunidades, y acerca de cómo avanzar el bien común. A nivel colectivo, muchas veces estos procesos parten de la base de que ciertos consensos, o verdades auto-evidentes, no podrán ser desconocidos. La Declaración Universal de Derechos Humanos de 1948 es un buen ejemplo de estos consensos básicos, y la mayoría de los procesos constituyentes de la post-guerra han considerado que estos catálogos son una premisa básica que el poder constituyente debe respetar ${ }^{5}$.

Sin embargo, lo fundamental de una democracia deliberativa, aquello que constituye su virtud epistémica, es el hecho de que la deliberación es capaz de transformar las opiniones 0 preferencias iniciales con que ingresamos al diálogo (asumiendo nuestra racionalidad imperfecta y limitada capacidad de acceder a información); que al consultar múltiples

En este sentido, la Declaración Universal de Derechos Humanos, así como otros tratados internacionales de derechos humanos, han sido considerados como elementos centrales por las recomendaciones de varios organismos internacionales que se han involucrado en procesos de creación constitucional. Hart (2003); Ghai y Galli (2010); UNDP (2014). saberes podemos incluir perspectivas que de otra manera no hubiéramos tomado en cuenta y que mejoran la imparcialidad y legitimidad de la decisión; o de que podamos corregir, en el marco de un procedimiento adecuado, los errores empíricos o falsas representaciones de la realidad. La concepción deliberativa de la democracia se ha presentado como una innovación de la democracia meramente mayoritaria, aquella que supone que el cálculo del número de representantes determinará las decisiones políticas (una democracia que se define únicamente por la regla de mayoría).

En términos generales, la teoría de la democracia deliberativa ha despertado diversos debates en torno a sus postulados principales: por ejemplo, a propósito de los arreglos u opciones institucionales que mejor los implementan (Fishkin 2011); acerca de si debemos concentrarnos en instituciones o procesos de toma de decisiones específicos, o acerca de los arreglos institucionales a nivel sistémico (Parkinson y Mainsbridge 2012); o acerca del rol del disenso y el desacuerdo, y sus posibles relaciones con la regla de mayoría (Waldron 1999). En el marco de procesos constituyentes, la democracia deliberativa busca organizar estos momentos constitucionales de modo que cumplan con los estándares de mayor deliberación que usualmente se le exigen.

\subsection{Democracia dualista}

Por su parte, para la teoría dualista de la democracia la relación entre democracia y constitucionalismo descansa en una legitimidad constitucional derivada de mayores exigencias democráticas (Ackerman 1998). De ahí la explicación y justificación de los quórums supermayoritarios de reforma constitucional, 
y de la existencia de órganos de control constitucional. Más aún, la teoría dualista acuñó el concepto de momentos constitucionales, que pueden reconocerse más allá de las instancias formales de reforma constitucional. En efecto, podemos también hablar de momentos constitucionales cuando la movilización popular o la intensidad del debate en la opinión pública desarrollan una cierta interpretación constitucional que posteriormente es internalizada por las instancias formales de decisión. En suma, la distinción entre momentos constitucionales y momentos de política ordinaria tiene como base una distinción entre mayores y menores requisitos democráticos.

En este trabajo, se excluirá el análisis de la relación entre momentos constitucionales e interpretaciones o evolución constitucional (es decir, el modo en que los momentos constitucionales influyen en el rumbo que una determinada constitución adopta). Antes bien, y en el contexto actual, lo que interesa es analizar la relación entre los momentos constitucionales y un proceso constituyente, es decir, el reemplazo de una constitución por una nueva. Lo que es crucial, en palabras de Klein y Sajó, es que los participantes de este proceso constituyente "están conscientes de que están involucrados en la creación de un derecho de máxima jerarquía y que por tanto esto crea expectativas, roles y reglas especiales" (2012: 420). En términos generales, los momentos constitucionales se caracterizan por lo siguiente:

primero, por el hecho que un extraordinario número de ciudadanos está seguro de la seriedad del asunto que se discute, seriedad mucho mayor que la seriedad que se otorga a las decisiones políticas normales; segundo, por el hecho de que todos los ciudadanos han tenido la oportunidad de organizarse para expresar su forma de ver el problema que se discute; y, tercero, por el hecho que existe una mayoría partidaria de una determinada forma de solucionar el problema en cuestión (Ackerman y Rosenkrantz 1991: 16; las negritas son nuestras).

Así, la distinción entre momentos constitucionales y momentos de política ordinaria determinaría la distinción entre pueblo y gobierno, respectivamente. En otros términos, podríamos señalar que en los momentos constitucionales es el pueblo el actor principal, por lo que a esas decisiones se les adjudica "la más alta legitimidad constitucional"; por su parte, en momentos de política corriente, el pueblo, que ya tuvo su rol protagónico, "confía al gobierno la gestión de los negocios públicos $\mathrm{y}$, el gobierno, legitimado por este mandato, adopta las decisiones que cree más convenientes" (Ackerman y Rosenkrantz 1991: 16). Si los momentos constitucionales reafirman el valor de la democracia directa o participativa, los momentos de política ordinaria quedan sujetos a los designios de la democracia representativa. A pesar de las múltiples críticas que ha recibido (Vargova 2005), la teoría dualista sigue apoyando un punto de particular relevancia para este trabajo: la deliberación en momentos constitucionales.

\section{Medios de comunicación y procesos constituyentes: Prensa escrita en Chile}

\subsection{Introducción}

Considerando las dos concepciones de la democracia recién expuestas, surge la pregunta por el rol de los medios de comunicación en procesos constituyentes. Para una concepción deliberativa de la democracia, la comunicación política mediada en la esfera pública puede facilitar los procesos de legitimación deliberativa en sociedades complejas sólo si se cumplen dos condiciones: un sistema de medios de 
comunicación auto-regulado que adquiere independencia con respecto a su entorno social, y si audiencias anónimas son capaces de garantizar la retroalimentación entre un discurso de elite informado y una sociedad civil responsiva (Habermas 2006: 411-412).

Estas condiciones constituyen el carácter reflexivo que debe tener la esfera pública, en donde los participantes pueden (re)visitar las opiniones públicas percibidas y responder a ellas después de (re)considerarlas. En este escenario, los medios de comunicación se erigen en verdaderos filtros que van limpiando la esfera pública, movilizando las demandas e informaciones consideradas como relevantes, y especificando las interpretaciones prevalentes sobre estos asuntos. Las etapas posteriores suponen que esta opinión pública reflexiva es incorporada en las estructuras discursivas institucionales. En resumen, para Habermas y otros teóricos de la democracia deliberativa, la garantía que deben ofrecer los medios de comunicación es la formación de una pluralidad de opiniones públicas examinadas que contribuyan a la formación de la esfera públicapolítica (Mauersberger 2016: 16-26; Habermas 2006: 416).

Por su parte, para la teoría dualista de la democracia, el rol de los medios de comunicación está sometido a diversos estándares, dependiendo del momento en que nos encontremos: para momentos de política ordinaria, el rol de los medios de comunicación coincide con las posturas de una concepción deliberativa de la democracia. Considerando que en momentos de política ordinaria la ciudadanía ha otorgado al gobierno el rol protagónico en la administración de los asuntos públicos, los medios de comunicación constituyen el principal intermediario entre la opinión pública (en la periferia) y el sistema político (en el centro) durante los períodos entre elecciones. Sin embargo, en momentos de política extraordinaria (momentos constitucionales), el rol de los medios de comunicación es aún más importante: se erigen en verdaderos canales de movilización de cuestiones públicas y foros deliberativos que colaboran en la conformación de diversas opiniones públicas sujetas a constante discusión.

Con este trasfondo de ideas, podemos someter a escrutinio el rol de los medios de comunicación en procesos constituyentes, si nos tomamos en serio los criterios que nos ofrece una concepción deliberativa/dualista de la democracia: la necesidad de sostener un debate público intenso, vigoroso, inclusivo, y extenso, que otorgue a la mayor cantidad de ciudadanos la posibilidad de tomar parte (directa $\mathrm{o}$ indirectamente) en este proceso constituyente. Más aún, esta concepción busca otorgar primacía a la deliberación ciudadana por sobre la experticia técnica, que funciona como complemento de la discusión política.

El desafío del actual proceso constituyente, por tanto, es lograr un balance adecuado entre las experticias técnicas, las destrezas disciplinares, y el rol principal que deben asumir los ciudadanos en la articulación de los ideales constitutivos, de los valores que constituirán la identidad de la comunidad política. En las primeras etapas del proceso constituyente, la pregunta por los valores fundantes, por la imaginación política, y por aquello que constituye la identidad común, se transforma en el eje fundamental. A diferencia de lo que nos ha enseñado la tradición del constitucionalismo liberal, las emociones, los sentimientos y las 
pasiones han jugado un rol fundamental en la configuración de las instituciones políticas (Sajó 2011; Walzer 2006).

En este contexto, es importante preguntarse si acaso la estructura y funcionamiento del mercado de los medios de comunicación en Chile es capaz de enfrentar los desafíos que plantea un proceso constituyente. ¿Están los medios de comunicación masivos preparados para enfrentar este desafío? ¿Están dando un espacio adecuado a voces e ideas diversas o subalternas? ¿Cómo están abordando los peligros de una potencial tecnificación de la discusión constitucional? ¿Cuán lejos estamos de los estándares que deberíamos observar en este tipo de procesos? Para contestar estas preguntas, es necesario, primero, hacer una breve síntesis del estado de la libertad de expresión en Chile, en lo que concierne al objeto de este trabajo.

\subsection{Libertad de expresión y prensa escrita en Chile}

Los rankings de libertad de prensa sitúan a Chile entre los paísesconmejoresgrados de protección a la libertad de expresión. Indicadores como el de Freedom House (2015) (Chile ocupa el tercer lugar en América Latina, después de Uruguay y Costa Rica), o los informes que anualmente publica Human Rights Watch, dan cuenta de un país en donde los medios de comunicación sufren pocas injerencias estatales, y en que los periodistas pueden ejercer su profesión sin un serio temor de ser víctimas de atentados a su vida, integridad o al ejercicio de su oficio. A pesar de que durante los últimos años Chile ha venido mostrando un descenso en estos rankings, motivado principalmente por los grados de movilización social que se han vivido desde el año 2011, el país sigue siendo, ante la comunidad internacional, un lugar donde se respeta la libertad de prensa (Contreras Vásquez \& Contreras 2012) 6 .

La paradoja, que surge de inmediato, se relaciona con la alta concentración de la propiedad de los medios de comunicación masiva, con la integración vertical y horizontal que se observa en la estructura de las empresas informativas, y en el decaimiento de la propiedad estatal o pública de los medios de comunicación (el estado financiero de TVN y la reciente desaparición del diario La Nación, que hoy continúa como medio digital, son ilustrativos al respecto; Zamorano 2012). Esto se ve agravado por el grado de convergencia digital que estamos observando, y que lleva a los grupos económicos a expandirse a diversos medios, aprovechando las actuales condiciones de producción y reproducción de la información (Noam 2015; Godoy 2015).

En otras palabras, lo que estos rankings de libertad de prensa excluyen es justamente lo que representa graves amenazas a la democracia chilena y que, entendemos, se exacerban en el contexto de un proceso constituyente. La ironía de la libertad de expresión, como señala Fiss (1999), ubica a Chile como caso de estudio: estos rankings obvian los problemas que emergen del hecho de que el Estado no es la única ni, muchas veces, la más peligrosa amenaza en contra del derecho a la libertad de expresión. La ironía de la libertad de expresión es que mientras más buscamos protegerla de injerencias estatales, o de aquellas que hacemos en nombre de otros

\footnotetext{
Sin embargo, el último informe de Reporters Without Borders (2015) da cuenta de un muy mal estado de la cuestión, ya que Chile ocupa el lugar 58, por debajo de países como Argentina o El Salvador. El año 2002, ocupaba el lugar 24.
} 
fines o bienes públicos, más desatendemos el "efecto silenciador" que puede tener la libre interacción de capitales privados en el mercado de los medios de comunicación.

Por su parte, la prensa escrita en Chile está afectada por un mal, presente desde los días posteriores al golpe de Estado de 1973: la desaparición de todos los diarios que no fueran El Mercurio o La Tercera (Bando $n^{\circ} 15$, Junta Militar). Una vez recuperada la democracia, los intentos por conformar un diario de circulación nacional (o metropolitano) que sirviera de contrapeso a los grupos comunicacionales hegemónicos fallaron estrepitosamente (Godoy 2015: 644646): ya fuere por los vetos de los avisadores, las dificultades que se encontraron en el mercado financiero, o por la falta de voluntad política o comprensión de la importancia del rol de los medios de comunicación en la configuración de la esfera pública.

En efecto, desde 1973, nunca se pudo volver al mercado de la prensa escrita que existía con anterioridad: uno que perfectamente se podría enmarcar en una concepción pluralista de la democracia. En otras palabras, un mercado en el que los partidos o colectividades políticas se relacionaban de manera explícita o implícita con algunos de los diarios de circulación nacional o metropolitana. Aquella concepción de la democracia fue reconocida en el Estatuto de Garantías Constitucionales (Ley $\mathrm{n}^{\circ}$ 17.398, de 9 de enero de 1971), que incorporó a la Constitución de 1925 diversos aspectos que ya se encontraban regulados en la Ley General de Elecciones de 1962: la posibilidad que tenían los partidos o movimientos de ser propietarios de medios de comunicación, y el derecho que tenían los partidos a utilizar los medios de comunicación de propiedad estatal de acuerdo a la representación parlamentaria (cuestión que también estaba regulada, de manera explícita, en la Ley de Televisión Nacional, $n^{\circ} 17.377$ de 1970).

Hoy en día, el mercado de la prensa escrita sigue los patrones de la realidad latinoamericana, que observa una estructura de alta concentración de medios dominados por familias con mucho poder político y con un marcado carácter conservador (Godoy 2015: 644). Sin embargo, la ausencia de un diario estatal o la falta de diversidad editorial conforman un mercado particular en el continente. En efecto, si aplicamos el criterio del paralelismo político, utilizado como indicador para evaluar comparativamente diversos sistemas de medios de comunicación en países desarrollados (Hallin y Mancini 2004), nos encontramos con un régimen político en que dos grandes coaliciones compiten por los escaños en el parlamento y el poder ejecutivo, pero cuyas posturas no se ven reproducidas en el sistema de medios de la prensa escrita (Mellado y Lagos 2013: 12).

En el presente escenario, y como lo muestran los indicadores de circulación, lectoría e inversión en publicidad (ACHAP), todos los diarios de circulación nacional (es decir, aquellos que se venden en todo el país), pertenecen a los dos grupos económicos que controlan el mercado: COPESA S.A. y EL MERCURIO S.A. (esto sin considerar la gran cantidad de diarios regionales que también dependen de estos grupos). ${ }^{7} \mathrm{La}$ concentración de medios de comunicación en Chile es creciente, y el caso de la prensa escrita presenta problemas particulares. Sin embargo,

Asociación Chilena de Agencias de Publicidad (http://www.achap. cl/estudios.php). Hoy en día es común referirse al "duopolio" de la prensa escrita en Chile (Godoy 2015). El informe del Instituto Nacional de Derechos Humanos (2013) utiliza esta misma expresión para diagnosticar el estado de la prensa escrita en Chile. 
ello es un fenómeno mundial que se ha visto amplificado por los fenómenos de una economía altamente internacionalizada y la convergencia digital (Noam 2015).

Para cierta postura, expresada en el famoso informe Hutchins (Commission on Freedom of the Press 1948), la concentración podría no ser problemática si acaso existiera suficiente diversidad editorial o si los medios fueran capaces de representar, en su estructura interna y accionar, la pluralidad de visiones en una sociedad. Sin embargo, la literatura sobre prensa escrita ya ha mostrado los peligros que esta concentración representa para la libertad de expresión y, en especial, para la calidad de la discusión o deliberación democrática (una completa lista de referencias bibliográficas sobre el caso chileno se puede encontrar en Arriagada y Navia 2013). La propia Comisión Interamericana de Derechos Humanos, a través de su relatoría para la libertad de expresión, ha insistido en este punto varias veces, señalando que las presiones económicas y la desregulación de este mercado son de las cuestiones más preocupantes para la próxima década. En una de las declaraciones conjuntas que firmaron varios relatores regionales y globales para la libertad de expresión, se destacaron los problemas que acarrea la concentración de la propiedad para la diversidad de opiniones (CIDH 2010). Encierto modo, lajustadistribución del poder comunicativo es considerada como incompatible con la concentración, independientemente de la diversidad que pueda observarse en mercados concentrados.

Un caso paradójico, en estesentido, lo representa el diario El Mercurio, que venía cubriendo extensamente la actividad de la Relatoría para la Libertad de Expresión, y que omitió referirse a la concentración de medios, optando por destacar otras declaraciones globales acerca de la regulación excesiva que se observa en Internet (CIDH 2011), o aquella que se refiere a los delitos contra la libertad de expresión (CIDH 2012). Del mismo modo, en el sitio web de El Mercurio no se encuentra información sobre la gran cantidad de ocasiones en que los informes anuales de la mencionada Relatoría han alertado sobre la concentración de la propiedad de los medios de comunicación, optando por cubrir sólo las situaciones de violencia en contra del periodismo o de injerencias estatales en el contenido de los medios.

Los diarios de circulación nacional no pueden obviar la cobertura de temas que son de evidente interés público, como la colusión de empresas que proveen de servicios o productos básicos para la población, o grandes movilizaciones sociales que ocupan espacios públicos relevantes para el imaginario nacional ${ }^{8}$. Más aún, en contextos de mercados concentrados, existen incentivos para separar la producción y seguimiento de noticias (un rol objetivo) y la expresión de preferencias políticas (subjetivas). En otras palabras, el diario no puede abiertamente mostrarse partisano o faccioso si quiere mantener o aumentar su capacidad de obtener ganancias, salvo cuando se trata del "capricho" de sectores adinerados que pueden sostener un medio a pesar de las pérdidas económicas.

Los diarios ciertamente influyen en la configuración de la agenda pública (agendasetting), pero en ello compiten principalmente con el gobierno y, en menor medida, con otros actores sociales que van desarrollando

Ver los trabajos de Moscoso 2014, y de Pérez (en el presente volumen), referentes al tratamiento de la prensa del movimiento estudiantil de 2011. 
la capacidad de instalar temas en la agenda pública a través de diversos medios (gremios, sindicatos, movimientos sociales, etc.). En ese rol, por ejemplo, se pueden destacar las redes sociales y los medios digitales, en tanto mecanismos que influyen en el contenido de los temas a discutir por los medios de comunicación masiva (Messner y Watson 2008). Sin embargo, los diarios, en tanto medios de comunicación masiva, pueden ejercer su periodismo militante (advocacy journalism) de múltiples maneras. Piénsese, por ejemplo, en las teorías del priming o framing, que han servido para hacer análisis sobre los sesgos políticos o de género en que usualmente incurren los diarios (Scheufele y Tewksbury 2007).

En un contexto de baja lectoría de diarios, como lo reafirman los datos de la ACHAP y los estudios de lectoría de medios escritos, cabe preguntarse por el rol que juegan estos medios (UDP 2010; CNCA 2011). Más allá de la capacidad de poner los temas en la agenda, los diarios sirven como articuladores de audiencias, en la medida en que otorgan de insumos (argumentos y evidencia) a una cierta opción política. De esta manera, es posible encontrar los mismos argumentos (y sobre todo las mismas falacias y estrategias) repetidas por los políticos de derecha para oponerse a cambiar la constitución y, sobre todo, a una asamblea constituyente (ver Ferreiro 2014).

Aun así, en términos generales, la teoría de usos y gratificaciones permite explicar el hecho de que la gente pueda seguir comprando diarios, a pesar del duopolio, pues puede distinguir y seleccionar aquello que anda buscando (Ruggiero 2000). En efecto, a pesar de que la gente califica a los diarios masivos como de centro o de derecha (o, en general, como poco independientes), quizás los deseos de la gente van por otros lados, como el deporte o las noticias policiales, las secciones más leídas en los diarios, sobre todo entre los quintiles de menores ingresos (UDP 2010; CNCA 2011). Peor aún, las secciones de opinión, representadas en la editorial o en las cartas al director o las tribunas, son las secciones menos leídas de los diarios (CNCA 2011: 127).

Todo ello nos lleva a sugerir que los dos principales diarios (además, debemos incluir a La Segunda) le hablan a una elite con capacidad de influir en las decisiones políticas del país (una elite, además, mayoritariamente urbana, masculina y con educación universitaria; véase CNCA 2011: 127-128). Además de hablarle a una particular audiencia, estos diarios buscan delinear los rangos de lo razonable ${ }^{9}$. En otras palabras, no sólo buscan poner ciertos temas en la agenda, sino además determinar el modo de abordar estos temas, influyendo en el modo en que las instituciones reaccionan ante los mismos. ${ }^{10}$ Así, por ejemplo, El Mercurio tiene

Como señala Habermas, "para votantes responsivos, que se involucran en la discusión política diaria, que leen los diarios, ven televisión, y que participan o no en las elecciones, las opiniones públicas consideradas presentan alternativas plausibles de qué es aquello que cuenta como una posición razonable sobre asuntos públicos" (2006: 418).

10 La ciencia política ha mostrado el modo en que las cortes, por regla general instituciones contramayoritarias, van siguiendo los cambios en la opinión pública, sobre todo en casos política o moralmente contenciosos (Friedman 2009). Más aun, en el contexto de conflictos políticos, los medios de comunicación son protagonistas en delinear lo que queda dentro del marco de lo políticamente posible, de aquello que se considera razonable, o institucionalmente correcto. El rol de la prensa brasileña en la reciente acusación constitucional contra la presidenta Dilma Rousseff ha ciertamente influido en los procedimientos judiciales (ante el Tribunal Supremo Federal), y jurídico-constitucionales (ante el Congreso), mostrando que el modo en que se articula la opinión pública y, a su turno, el modo en que las instituciones reaccionan, pueden convertirse en el factor político principal. Así, por ejemplo, la prensa brasileña, extremadamente concentrada en algunas pocas familias con una marcada preferencia política, ha sido calificada como uno de los principales articuladores del denominado "golpe blanco" (Undurraga 2016). 
una capacidad de influir indirectamente en el modo de entender el debate sobre la colusión: si acaso como una cuestión criminal de interés nacional (propia del cuerpo $\mathrm{C}$ ), de carácter político que exige una reflexión más profunda (pertinente para el Cuerpo de Reportajes), o como un suceso noticioso del ámbito de la economía y los negocios (cuerpo B) ${ }^{11}$. O, del mismo modo, puede asociar el proceso constituyente con inestabilidad, incertidumbre y bajo crecimiento económico, antes que con ejercicio de ciudadanía, deliberación y democracia (ver Ferreiro 2014).

Más aún, como señalan Gronemeyer y Porath (2013), los diarios de circulación nacional con base en la Región Metropolitana son homogéneos en relación a los temas editorializados, si se comparan con los medios regionales. El Mercurio, La Tercera y La Segunda observan una gran homogeneidad que prioriza "temas de gobierno central y organizaciones públicas, además de tópicos económicoempresariales", por sobre "temas de gobierno regional y local", pero también "se observa que los tres diarios dan una visibilidad mínima a temas de salud, vivienda y políticas sociales y a los de trabajo, gremio y consumidores". Como concluyen ambos autores, "la compartida visibilidad de unos temas y la casi invisibilidad de otros avalaría la tesis de un duopolio ideológico en la prensa chilena" (2013: 444). Además, podríamos agregar, de los temas políticamente

El ejemplo del 'perdón' dominical de Eliodoro Matte, a propósito del caso de la colusión del confort, es ilustrativo. La entrevista a fondo con Matte, que tiene una estrecha relación con los propietarios de El Mercurio, se incluyó en el cuerpo B (Economía y Negocios) y no en el cuerpo D (reportajes). Véase la entrevista en el siguiente link: http://impresa.elmercurio.com/pages/ LUNHomepage.aspx?BodyID=2\&dt=2015-11-01\&dtB=2015-11$01 \& d t B=01-11-2015$ relevantes de los que debe hacerse cargo el gobierno central.

A pesar de constituir esfuerzos encomiables para mitigar los efectos nocivos de la concentración de medios, los medios digitales siguen siendo una excepción y muestran bajos índices de lectoría. Por su parte, el actual proyecto de ley de medios digitales ha sido descrito por algunos expertos como una amenaza a la libertad de expresión, y sería incapaz de dar cuenta del aporte que pueden realizar los mismos (Derechos Digitales 2015). Además, como lo muestran ciertos estudios recientes, la lectoría de medios digitales y la utilización de redes sociales como mecanismo de participación social y política sigue siendo una excepción: los medios digitales alternativos [a los grandes grupos empresariales que dominan el mercado] no tienen la capacidad de producir una noticia y monitorearla de manera permanente, de modo que se erigen en "ecos" de lo que los medios dominantes producen (Couso 2011).

Las evidencias encontradas hasta el momento muestran que "el consumo de medios digitales está fuertemente asociado a un mayor activismo político y social" (Scherman, Arriagada y Valenzuela 2010: 17). Sin perjuicio de que ello puede representar una manera de profundizar y amplificar los deseos de participación de quienes ya sienten una inclinación inicial hacia lo público, estos estudios muestran el rol que los medios digitales pueden cumplir en la modificación de la concepción tradicional de la democracia representativa. De todos modos, aún falta mayor investigación sobre el rol y el impacto de los medios digitales, aunque no se ha observado un cambio significativo en la estructura del mercado de las comunicaciones en Chile. 


\subsection{Medios de comunicación y procesos constituyentes}

Este es un tema prácticamente inexplorado por la literatura comparada. Incluso en casos de democracias pluralistas con importantes grados de participación, y que cuentan con avanzados modelos de propiedad pública de medios de comunicación, los procesos constituyentes han minimizado el rol que juega la prensa.

El caso del referéndum por la independencia de Escocia, que tuvo lugar en Septiembre de 2014, suponía que un eventual triunfo del SI activaba un proceso constituyente de manera inmediata. Producto del Acuerdo de Edimburgo, el gobierno del Reino Unido y el gobierno que administra los poderes devueltos en Escocia, omitieron referirse a la regulación de los medios de comunicación (posteriormente, en la Scottish Referendum Act, las cuestiones relativas a las campañas y a los gastos en publicidad y avisaje fueron deferidas a la Comisión Electoral). En general, se entendió que la regulación y escrutinio sobre la British Broadcasting Television (BBC) ${ }^{12}$, y la existencia de un organismo regulador independiente para el resto de las comunicaciones(OfCom, Independent regulator and competition authority for the UK communications industries) eran garantía suficiente de la imparcialidad, transparencia y difusión de la posturas del referéndum. Para el caso de la prensa escrita, quedaban vigentes los estándares contenidos en la Royal Charter on Self Regulation of the Press, que busca que la autoregulación (individual o colectiva) que establezcan

\footnotetext{
La BBC emitió directrices especiales para el caso del referéndum en Escocia, en consonancia con los principios del Acuerdo de Edimburgo. A pesar de ello, hubo diversas críticas en torno al sesgo de la BBC para apoyar la unidad del Estado del Reino Unido que fueron presentadas ante los organismos regulatorios correspondientes tanto por el Partido Nacionalista Escocés como por el Sindicato Nacional de Periodistas.
}

los actores privados sea independiente (tanto del gobierno y los actores políticos como de los propios medios regulados) y efectiva ${ }^{13}$. Quizás confiados en que ambas posturas tendrían un apoyo financiero y mediático lo suficientemente poderoso, esta decisión supuso estándares amplios que garantizaran la transparencia y la imparcialidad del referéndum.

Recordemos que en el Reino Unido, los diarios, por regla general, manifiestan explícitamente su apoyo a los partidos o posturas durante las elecciones. Para el caso del referéndum escocés, todos los diarios británicos, a excepción del Sunday Herald escocés, expresaron su apoyo por el NO, minimizando la visibilidad de quienes apoyaban la independencia. Si consideramos que tanto las radios como la televisión se ven afectadas por la agenda configurada por los diarios, la polémica quedó instalada, pero pasó a segundo plano por el repunte del $S /$ y los resultados finales, que mostraron un apoyo masivo por la postura independentista (Monbiot 2013).

El ejemplo de Islandia es también elocuente: ante la proliferación de candidaturas (522) para elegir a los miembros de la asamblea constituyente que nacería a propósito de la crisis de legitimidad que se gatilló por la reciente crisis financiera, el canal de televisión pública (RúV) decidió no dar cobertura a ninguna candidatura. Las semanas previas a la elección decidió dar una cobertura general y no pormenorizada de las candidaturas, arguyendo que ello resultaba complejo para la infraestructura y servicios que prestaba el canal (de acuerdo a una encuesta, sólo el 35\%

\footnotetext{
A propósito del escándalo de la interceptación de comunicaciones telefónicas por diarios británicos (2011), la Cámara de los Comunes creó la comisión Levenson, que estableció este Decreto Real, aspirando a mejorar los organismos auto-reguladores de la prensa escrita (Tomlinson 2014).
} 
del electorado había declarado tener algún contacto con las candidaturas). El día anterior a la elección de los miembros, el denominado canal transmitió un programa de interés público que abordó temas que nada tenían que ver con el proceso constituyente. La elección contó con una de las más bajas participaciones electorales en la historia de Islandia (sólo un 35,5\% concurrió a votar, a diferencia de las elecciones parlamentarias que se realizaron casi en las mismas fechas, en que la nueva constitución fue uno de los temas centrales, y que contaron con una participación del $81 \%$ del electorado).

Como concluyó un reciente estudio sobre el tema, "Rúv y el resto de los medios de comunicación islandeses ubicaron el tema de la asamblea constituyente en un lugar secundario en sus agendas, y al hacer eso disminuyeron la legitimidad de la elección de los miembros de la misma a los ojos del público" (Guðbjorg 2012: 384). Como se ha repetido en otras instancias, el poder de setear la agenda implica grandes responsabilidades, y la particular posición que ocupan los medios de comunicación masiva nos llevan a preguntar por sus roles públicos en el marco de un proceso constituyente. Más allá de que existen diferentes grados de autonomía que se pueden exigir a los medios públicos y privados (OSCE 2012), las lecciones del caso islandés no deben pasar desapercibidas para el caso chileno que recién comienza. Las preguntas, antes que jurídicas, se relacionan con los estándares éticos del periodismo y con la necesidad de ver cómo la prensa configura los límites de lo políticamente posible en un proceso constituyente que exige un debate robusto, sincero e inclusivo.

Si en el debate sobre la constitucionalidad de la franja electoral que se exige a los canales de televisión para las elecciones primarias, el
Tribunal Constitucional chileno (rol 2487-13) fue enfático en señalar que los procesos electorales deben otorgar espacio a la más amplia deliberación, de modo que el sufragio sea el resultado de un "ejercicio informado", entonces cabe preguntarse si existirá o no algún debate sobre el rol de la prensa escrita en difundir, por ejemplo, cuestiones básicas referidas al proceso constituyente. Tal como los diarios masivos deben incluir las listas de vocales de mesa, o la información acerca de los registros electorales, cabe preguntarse si acaso existirá alguna medida en torno a garantizar la difusión de cuestiones básicas para el éxito del proceso constituyente.

Ya sea a través de un financiamiento público (avisaje estatal) equitativamente distribuido, o de una verdadera carga pública, los diarios de circulación nacional deben jugar un rol más activo ("involucramiento activo", en palabras de Fuentes y Joignant 2015: 317). Más aún, y considerando el rol de los medios de comunicación como espacios de reflexión y deliberación pública, el desafío para los diarios es mayor. Los diarios constituyen un modo particularmente relevante para el ejercicio de la deliberación, pues permiten articular argumentos de manera pausada, involucrarse en debates con la posibilidad de otorgar razones de diverso tipo, y contrastar las opiniones con otro tipo de informaciones. Lo que no podemos hacer, en este contexto, es dejar de reflexionar sobre el especial rol que puede corresponder a la prensa escrita en una democracia que atraviesa momentos excepcionales como la chilena.

Como vimos en la sección anterior, los diarios de circulación nacional, con base en la Región Metropolitana, se constituyen en verdaderos filtros deopinión pública que interactúan con elites urbanas, masculinas e ilustradas, articulando 
los discursos de las posiciones políticas que se considerarán razonables sobre los asuntos públicos. La siguiente sección busca mostrar el modo en que un diario escrito de circulación nacional y un medio digital han abordado el tema del proceso constituyente, contribuyendo de manera gradual a fijar las posiciones que se van a considerar políticamente razonables.

\section{Análisis de discurso asistido por corpus}

La lingüística de corpus se caracteriza por analizar grandes volúmenes de textos que constituyen un corpus. La principal ventaja práctica de este procesamiento es, que de otro modo, tomaría demasiado tiempo para quien realice la investigación el leer y analizar dichos textos uno por uno. Para ello se utilizan distintos programas computacionales que permiten rápidamente contar frecuencias de palabras o grupos de palabras, buscar todas las ocurrencias de alguna palabra en específico en su contexto inmediato (concordancia), encontrar las palabras con las que se asocia una palabra específica, comparar distintos corpora (plural de corpus), entre otras herramientas. Todo esto se aplica a distintas áreas, en la medida en que el encontrar patrones estadísticamente significativos en grandes volúmenes de textos puede utilizarse prácticamente en cualquier campo de investigación sobre el lenguaje.

Una de las ramas de la lingüística donde se aplican los métodos de lingüística de corpus es el Análisis Crítico de Discurso (ACD) ${ }^{14}$. Una de

\footnotetext{
Existe una propuesta de llamarlos Estudios Críticos de Discurso (ECD) en vez de Análisis Crítico de Discurso (ACD). Para los efectos de este artículo nos quedaremos con la segunda denominación, que ha sido usada más ampliamente y hace más tiempo. No obstante, una buen resumen de la argumentación favorable a llamarlos ECD puede encontrarse en Wodak y Meyer 2015.
}

las principales críticas que se le ha elaborado al ACD es el sesgo en la selección de datos a analizar (cherry-picking, como se le conoce en inglés). En otras palabras, se seleccionan aquellos textos que mejor prueban el punto que quiere demostrarse en la investigación, ignorando aquellos que lo contradigan. En este sentido, el uso de metodologías de corpus facilita una mejor representatividad y diversidad en los textos a analizar, limitando dicho sesgo (Mautner 2015: 172).

El Análisis (Crítico) de Discurso asistido por métodos de lingüística de corpus se ha desarrollado en los últimos diez años (Baker 2007; Baker et al. 2011; Baker y McEnery 2005; Mautner 2009; Orpin 2005) probando ser una combinación útil en la cual la lingüística de corpus permite lidiar con grandes volúmenes de texto y sortear mejor los problemas de sesgo de selección de los datos a analizar. Por otra parte, la mayor debilidad de ésta, a saber la pérdida del contexto en el análisis, puede sortearse con el complemento que da una mirada más detallada, propia de los métodos tradicionalmente cualitativos del Análisis de Discurso ${ }^{15}$.

Para los efectos de este artículo, las limitaciones de extensión impiden complementar con un Análisis Crítico de Discurso cualitativo. No obstante, la contextualización y revisión realizadas en las secciones anteriores permiten tener una mejor idea del detalle y contexto de los eventos ocurridos en el período analizado.

Para la realización del análisis crítico de discurso en prensa asistido por corpus, se seleccionó el período entre el 14 de octubre

\footnotetext{
Un ejemplo de esta puede verse en Ferreiro y Wodak 2014.
} 
de 2015 (día siguiente al anuncio presidencial de los pasos a seguir para crear la nueva constitución) y el 26 de marzo 2016, día en que se comenzó el proceso de análisis. Luego, se utilizó el buscador de noticias LexisNexis para buscar contenidos de los diarios El Mercurio y La Nación en dichas fechas que tuvieran el concepto nueva constitución. Decidimos utilizar este concepto ya que es capaz de englobar tanto el debate sobre proceso constituyente impulsado por el gobierno como las demandas por una asamblea constituyente, en vista que el fin de ambos es una nueva constitución.

Con esto se elaboraron dos bases de datos, correspondientes a cada diario. El Mercurio arrojó 153 textos, con un total de 129.014 palabras. La Nación generó una base de 49 textos con un total de 20.914 palabras. Esto significa que, en promedio, los textos de El Mercurio tienen casi el doble de palabras que los de La Nación, siendo la primera diferencia observable entre las bases. Ambas bases fueron almacenadas en formato texto (.txt) para su posterior análisis con el programa computacional AntConc (Anthony 2014). Vale decir que la cantidad de palabras es relativamente baja comparando con los estudios que tradicionalmente se hacen en lingüística de corpus, lo que puede presentar algunas limitaciones de las que nos haremos cargo explícitamente.

Tabla 1: Descripción de datos a analizar

\begin{tabular}{|l|c|c|}
\hline & El Mercurio & La Nación \\
\hline No. de Textos & 153 & 49 \\
\hline No. de Palabras & 129.014 & 20.914 \\
\hline Promedio Palabras por Texto & 843,2 & 427,6 \\
\hline No. de Palabras Distintas & 11.617 & 3.509 \\
\hline
\end{tabular}

Fuente: Elaboración propia

\subsection{Frecuencias totales}

A continuación presentaremos una tabla con un resumen de las palabras más frecuentes en la base de datos analizada. Por razones de espacio y parsimonia, presentaremos una selección de entre las 50 palabras más frecuentes, de las cuales excluimos las palabras gramaticales (pronombres, artículos, etc.), para concentrarnos en las léxicas. Este último criterio lo utilizaremos para todas las herramientas de lingüística de corpus (Hunston 2006). Se normaliza también la frecuencia de cada palabra por cada mil palabras, a modo de tener una comparación frente a muestras de tamaños disímiles.

Palabras como constitución, nueva, proceso, gobierno, constitucional, presidenta son comunes a ambos diarios, siendo la única diferencia dentro de esta selección de palabras 
Tabla 2: Palabras más frecuentes

\begin{tabular}{|ccc|ccc|}
\hline \multicolumn{2}{|c|}{ Palabras más frecuentes El Mercurio } & \multicolumn{3}{c|}{ Palabras más frecuentes La Nación } \\
Frecuencia & Palabra & $\mathbf{* 1 0 0 0}$ palabras & Frecuencia & Palabra & *1000 palabras \\
558 & constitución & 4.3251120033 & 129 & constitución & 6.1681170508 \\
510 & nueva & 3.9530593579 & 107 & nueva & 5.1161901119 \\
485 & gobierno & 3.7592819384 & 107 & proceso & 5.1161901119 \\
475 & proceso & 3.6817709706 & 77 & bachelet & 3.6817442861 \\
255 & presidenta & 1.9765296789 & 73 & presidenta & 3.4904848427 \\
253 & constitucional & 1.9610274854 & 70 & constituyente & 3.3470402601 \\
& & & 62 & gobierno & 2.9645213732 \\
& & & 50 & constitucional & 2.3907430429 \\
\hline
\end{tabular}

Fuente: Elaboración propia

que bachelet y constituyente tienen una mayor frecuencia relativa en La Nación que en El Mercurio. En términos generales, este grado de concordancia entre ambos diarios habla de que se trata de contenidos que están refiriendo a los mismos grandes temas y con frecuencias relativamente semejantes. Esto refrenda la comparabilidad entre ambos diarios para poder fijarnos en las diferencias más finas donde se pueden apreciar las diferencias de enfoque para tratar un mismo hecho socialmente relevante.

\subsection{Análisis de keywords}

Las keywords son aquellas palabras que, desde un punto de vista estadístico, se encuentran significativamente más en un texto (o conjunto de textos) que en otro texto (o conjunto de textos). En este caso, se procedió a comparar las noticias de El Mercurio con las de La Nación, ambas recolectadas con los mismos parámetros indicados al comienzo de la sección 4. Las keywords encontradas deben interpretarse entonces como aquellas palabras más propias de cada diario al compararlas con el otro diario. Esto significa que es posible que existan palabras de alta frecuencia en ambos diarios que no aparezcan como keywords en ninguno de los dos. La interpretación de dicho fenómeno es que la ocurrencia de dichas palabras se encuentra repartida de manera relativamente similar en ambos, y por ende, no son propias de ningún diario en particular.

La potencia de esta herramienta radica en poder identificar cuáles son los patrones (si es que los hay) de cada diario (al compararlo con el otro) para escribir sus contenidos sobre la nueva constitución. En este sentido la lectura que debe hacerse en la interpretación es doble: por un lado, las keywords de un diario son las palabras que dicho diario utiliza significativamente más que el otro. Por otro lado, son también las palabras que el otro diario no utiliza. En otras palabras, nos indican las palabras que un diario dice y que el otro silencia.

El estadístico utilizado es log-likelihood (por defecto en AntConc, y el más utilizado en esta herramienta). Se optó por observar sólo aquellas 
palabras con una frecuencia mínima de cinco (que estén al menos cinco veces en el texto), y sólo aquellas con un puntaje mayor al valor crítico de corte (3.840) para una significación estadística por sobre el $95 \%$, esto es $\mathrm{p}<0.05$ (ver Baker, 2007).

A continuación presentaremos los resultados de las principales keywords encontradas en cada diario. Como se hace imposible mostrar y analizar las 99 (en El Mercurio) y 184 (en La Nación) palabras que estaban por sobre el umbral crítico antes mencionado, mostraremos una selección dentro de las primeras 50 palabras, en las que excluiremos preposiciones y adverbios, para concentrarnos en los sustantivos, adjetivos y algunos de los verbos con mayor valor léxicodiscursivo (esto es, en oposición a las palabras cuya función es principalmente gramatical).

Tabla 3: Keywords El Mercurio

\begin{tabular}{|cc|c|}
\hline Frecuencia & Puntaje Estadístico & Keyword \\
\hline 65 & 19565 & ppd \\
53 & 15953 & recursos \\
46 & 13846 & izquierda \\
46 & 13846 & segpres \\
223 & 12674 & consejo \\
62 & 12328 & ps \\
39 & 11739 & propiedad \\
129 & 11215 & lagos \\
35 & 10535 & tc \\
34 & 10234 & encuentros \\
33 & 9933 & orden
\end{tabular}

Fuente: Elaboración propia
Lo primero que es posible de observar es que en El Mercurio se nombran más los partidos políticos, en particular los vinculados a la coalición de gobierno ( $p s, p p d$ ). No hay partidos de oposición dentro de las keywords de El Mercurio. La palabra recursos se explica porque El Mercurio habla significativamente más acerca del tema del financiamiento del proceso constituyente (recursos económicos). El Mercurio también utiliza significativamente más la palabra izquierda en sus contenidos donde figura la nueva constitución. Al examinar más de cerca, es posible comprobar que hay una referencia directa a los sectores políticos de izquierda como los impulsores/interesados en cambiar la actual constitución. La aparición de segpres en tanto keyword en El Mercurio refiere a que se establece dicho ministerio como el responsable de llevar adelante el proceso. Que su uso sea significativamente mayor en El Mercurio es consistente con los argumentos que temen que este proceso pueda ser manipulado por el gobierno. Ejemplos de ellos pueden observarse en la siguiente imagen.

Tanto consejo como encuentros refieren a la orgánica del proceso constituyente. Puntualmente, se alude al Consejo Ciudadano de Observadores y a los encuentros o cabildos que se realizarán a nivel local, provincial y regional.

El Mercurio centra gran parte de su preocupación en torno a lo que sucederá con el derecho de propiedad en la nueva constitución. Esto, sumado a que no hay ninguna mención a ella en La Nación, explica la aparición de la palabra propiedad como keyword. En esta misma línea, tc emerge como keyword por una preocupación semejante que El Mercurio expresa con respecto al futuro del Tribunal Constitucional (TC) en la nueva constitución. 


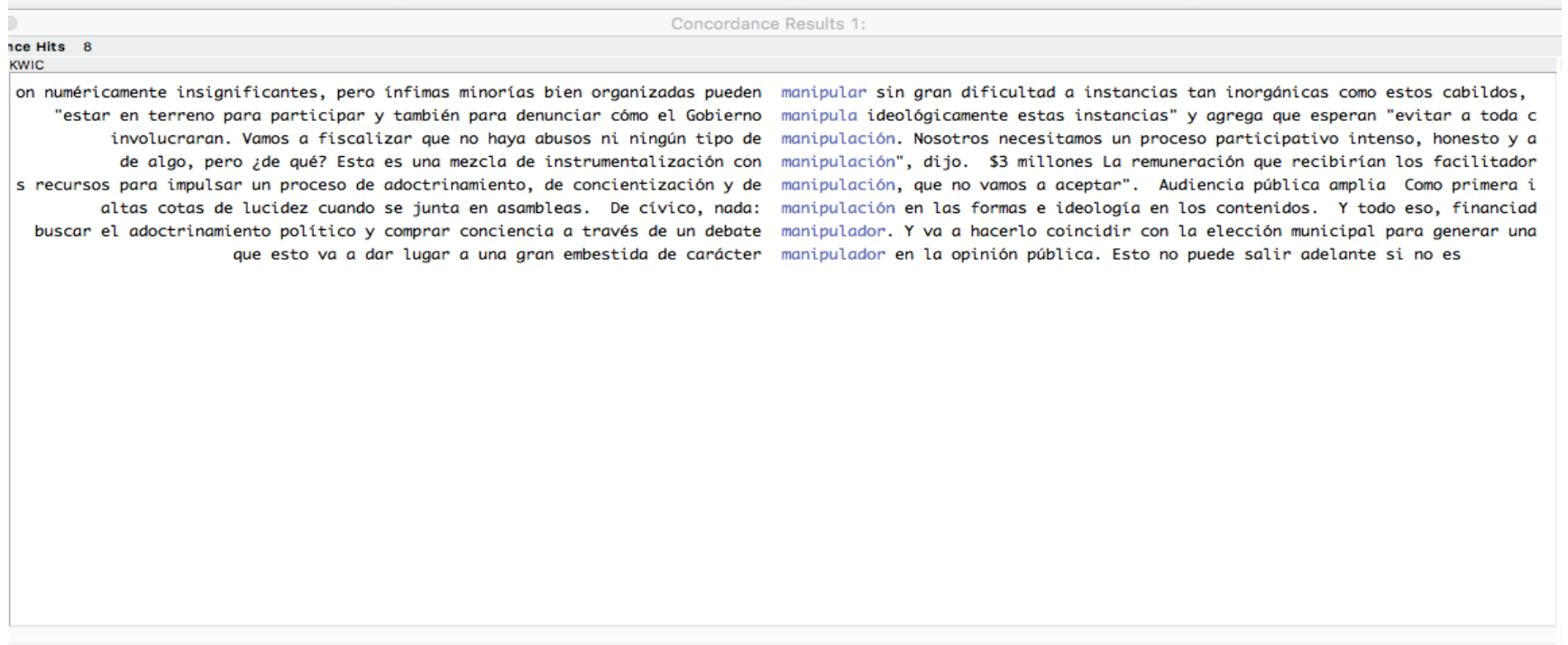

La figura del ex-presidente Ricardo Lagos es significativamente más referida por El Mercurio, explicando la existencia de lagos en tanto keyword. En varias de las ocurrencias se le refiere en tanto autor de la constitución del 2005. Dicho argumento (que la constitución actual no es la de 1980, si no que "la de Lagos 2005") ha sido utilizado por opositores a una nueva constitución, para decir que la constitución actual fue hecha en democracia, y por lo tanto no tiene problemas de legitimidad de origen. Adicionalmente quitó enclaves autoritarios como el Consejo de Seguridad Nacional, los senadores designados y vitalicios. En otras de las ocurrencias aparece mencionado como candidato presidencial. En sólo una de las 129 ocurrencias de lagos aparece mencionado en tanto cabeza de la plataforma tuconstitucion.cl que recaba opiniones en torno a una nueva constitución.
Tabla 4: Keywords La Nación

$\begin{array}{ccc}\text { Frecuencia } & \text { Puntaje Estadístico } & \text { Keyword } \\ 29 & 105682 & \text { cadem } \\ 77 & 62957 & \text { bachelet } \\ 22 & 47897 & \text { rechazo } \\ 15 & 47330 & \text { twitter } \\ 35 & 33360 & \text { ciudadanía } \\ 10 & 32961 & \text { encuestados } \\ 10 & 32961 & \text { paro } \\ 23 & 31599 & \text { aprobación } \\ 8 & 31489 & \text { clasista } \\ 8 & 31489 & \text { mercuriovalpo }\end{array}$

Fuente: Elaboración propia 
Al comparar con El Mercurio, La Nación le da una cobertura mayor a las encuestas semanales de CADEM, razón por la cual aparecen varias keywords asociadas a ellas, como cadem, rechazo, encuestados, aprobación y además, parte importante de las menciones a Bachelet tiene que ver con sus cifras de aprobación y rechazo en dicha encuesta. En la sección siguiente veremos la relevancia para el tema de la nueva constitución de que sólo La Nación cubra la encuesta Cadem mientras El Mercurio decide no hacerlo.

La Nación parece cubrir significativamente más que El Mercurio las discusiones en redes sociales. La aparición de twitter como keyword sería indicativo de esto. En esta misma línea, La Nación cubrió una de estas polémicas en twitter, que refería a una caricatura en el diario El Mercurio de Valparaíso. ${ }^{16}$ Dicha caricatura fue calificada como clasista por un gran número de usuarios de redes sociales. Esto explica también la aparición de mercuriovalpo y clasista.

El paro nacional organizado por la CUT (en donde se exigía una nueva constitución, entre otras cosas) también tuvo una cobertura significativamente mayor en La Nación que en El Mercurio. Por último, y refrendando hallazgos en estudios previos similares (Ferreiro 2014), la palabra ciudadanía aparece significativamente mucho más en La Nación que en El Mercurio en aquellos contenidos que refieren a la nueva constitución.

\subsection{Análisis de colocaciones}

Las colocaciones son palabras que, desde un punto de vista estadístico, tienden a ocurrir

Esta caricatura hacía referencia a una empleada doméstica que le anunciaba a sus jefes que iba a formar parte de los encuentros o cabildos para la nueva constitución. juntas en un texto. En este caso, se utilizó el estadístico mutual information (MI), el que viene por defecto en el programa AntConc. El estadístico $\mathrm{MI}$ tiende a privilegiar más las palabras léxicas que las gramaticales, en la medida que se privilegia la exclusividad de la relación entre las palabras (esto es, que la palabra de la colocación no ocurra con otras palabras) por sobre la frecuencia de la colocación (ver Stubbs 1995).

Se consideraron colocaciones con una frecuencia mayor a cinco $^{17}$ y que se ubicaran hasta cinco palabras antes y cinco después de las palabras buscadas, opción que también viene dada por defecto en AntConc. Se buscaron las colocaciones de Constitución y Preocupa* en ambos diarios, para proseguir con la comparación y observar diferencias en cómo cada diario tiende a acompañar cada uno de estas palabras.

\subsubsection{Constitución}

La primera palabra que nos interesó fue constitución, por ser evidentemente la que está en el eje del debate de una nueva constitución. Como se dijo anteriormente, el criterio para levantar los textos era que ellos contuvieran las palabras "nueva constitución". Esto también asegura una alta frecuencia de ocurrencias de "constitución" y por lo tanto, mayor posibilidad de analizar sus distintas colocaciones.

17 Dado que el volumen de textos y palabras es significativamente mayor en El Mercurio que en La Nación, es de esperar también que el volumen de colocaciones que cumplan con la frecuencia mínima de cinco ocurrencias sea menor también en La Nación. Si bien esto limita la cantidad de palabras que pueden analizarse, decidimos mantener consistencia con los criterios. 
Tabla 5: Colocaciones "constitución" en ambos diarios

\begin{tabular}{|c|c|c|c|c|c|c|c|c|c|}
\hline \multicolumn{5}{|c|}{ Colocaciones Constitución El Mercurio } & \multicolumn{5}{|c|}{ Colocaciones Constitución La Nación } \\
\hline Frec. Total & Frec. Izquierda & Frec. Derecha & Puntaje Estadístico & Colocación & Frec. Total & Frec. Izquierda & Frec. Derecha & Puntaje Estadístico & Colocación \\
\hline 9 & 7 & 2 & 7.32253 & necesitamos & 84 & 84 & 0 & 6.99456 & nueva \\
\hline 307 & 303 & 4 & 7.12079 & nueva & 5 & 5 & 0 & 6.85828 & necesita \\
\hline 10 & 9 & 1 & 7.00505 & elaborar & 7 & 7 & 0 & 6.45063 & cambiar \\
\hline 11 & 10 & 1 & 6.85305 & modificar & 6 & 6 & 0 & 5.40511 & hacer \\
\hline 8 & 8 & 0 & 6.85305 & ciudadanas & 9 & 8 & 1 & 5.30418 & tener \\
\hline 6 & 6 & 0 & 6.53112 & elaboración & 5 & 3 & 2 & 5.14208 & cree \\
\hline 6 & 6 & 0 & 6.53112 & conceptos & 7 & 3 & 4 & 4.59648 & pais \\
\hline 7 & 2 & 5 & 6.01655 & democrática & 6 & 4 & 2 & 4.57112 & hay \\
\hline 10 & 8 & 2 & 6.00505 & generar & 6 & 2 & 4 & 3.18721 & proceso \\
\hline 7 & 5 & 2 & 5.80242 & cambiar & & & & & \\
\hline 6 & 2 & 4 & 5.79415 & requiere & & & & & \\
\hline 28 & 13 & 15 & 5.74154 & actual & & & & & \\
\hline 6 & 5 & 1 & 5.53112 & torno & & & & & \\
\hline 7 & 6 & 1 & 5.53112 & necesario & & & & & \\
\hline 19 & 12 & 7 & 5.53112 & idea & & & & & \\
\hline 8 & 8 & 0 & 5.49549 & económico & & & & & \\
\hline 6 & 3 & 3 & 5.35055 & fuerza & & & & & \\
\hline 6 & 6 & 0 & 5.30873 & hacia & & & & & \\
\hline 14 & 13 & 1 & 5.25101 & comisión & & & & & \\
\hline 8 & 8 & 0 & 5.09816 & público & & & & & \\
\hline 6 & 5 & 1 & 5.08046 & partidario & & & & & \\
\hline 8 & 3 & 5 & 5.04569 & sería & & & & & \\
\hline 17 & 16 & 1 & 5.02165 & proyecto & & & & & \\
\hline 5 & 1 & 4 & 4.96552 & misma & & & & & \\
\hline 6 & 2 & 4 & 4.94616 & mecanismo & & & & & \\
\hline 7 & 5 & 2 & 4.93248 & contenidos & & & & & \\
\hline 6 & 3 & 3 & 4.88342 & quiere & & & & & \\
\hline 17 & 13 & 4 & 4.86369 & debate & & & & & \\
\hline 5 & 4 & 1 & 4.78266 & legitimidad & & & & & \\
\hline
\end{tabular}

Fuente: Elaboración propia

Como es de esperar, nueva es de las primeras colocaciones de constitución en ambos diarios. Aunque en El Mercurio ocupa el segundo lugar tras necesitamos. En el caso de La Nación, se utiliza el verbo en tercera persona, necesita, y está en segundo lugar.

Imagen 2: Tabla de concordancias "necesitamos" y "constitución" en El Mercurio

\footnotetext{
cambios constitucionales", afirma Larraín, y recalca: "En Chile, claramente no necesitamos una nueva Constitución. Este proceso constituyente indudablemente qu El_Mercurio pero "no hubo por el lado nuestro una pelea acérrima, intensa, de decir que no necesitamos una nueva Constitución", puntualizó. Más que oponerse a raja tabla a El_Mercurio - me he opuesto a que comience con una conclusión anticipada que es aquella que necesitamos una nueva Constitución. El proceso constituyente debiese abrirse a m El_Mercurio. as fuerza que va a tener el proceso constituyente? -La Presidenta ha dicho que necesitamos una nueva Constitución, que necesitamos un techo de todos, que esta El_Mercurio na que mejora los sistemas de rendición de cuentas. - ¿Y qué pasa con la actual Constitución? ¿Es legítima o no? -Necesitamos una nueva Constitución porque est El_Mercurio uerza que señala, ¿no la ha planteado el Gobierno? -Le escucho al Gobierno que necesitamos una nueva Constitución porque la actual no goza de prestigio y eso e El_Mercurio

del Senado, Alfonso de Urresti (PS), señaló que "no hay lugar a dudas de que necesitamos una nueva Constitución democrática y debatida entre todos los sector El_Mercurio_
} 
Al observar más de cerca esta colocación, es posible ver que en El Mercurio estas ocurrencias responden a entrevistas, en las cuales hay tres entrevistados que se oponen a la necesidad de una nueva constitución. Dos entrevistados defienden la idea y otros dos reportan que tal necesidad es dicha por el gobierno/la presidenta.

En el mismo sentido, al explorar las concordancias de la colocación necesario es posible observar que negar la necesidad de una nueva constitución es aún más fuerte.

De las siete concordancias, hay una que no refiere a la necesidad de modificar la constitución. Las seis restantes corresponden a una entrevista a Sergio Muñoz (en ese entonces presidente de la Corte Suprema) en la cual manifiesta que no es necesario modificar la constitución para otorgar mayores derechos sociales; a parlamentarios de derecha que al día siguiente se muestran de acuerdo con lo dicho por él en dicha entrevista; y a una entrevista a Raúl Bertelsen, ex-presidente del Tribunal Constitucional y redactor de la comisión encargada de la redacción de la constitución de 1980, quien se muestra en desacuerdo con cambiar la constitución. Podemos decir que cuando El Mercurio refiere a lo necesario de cambiar la constitución, presenta sólo opiniones que se oponen a esto.

Como habíamos mencionado al comienzo de esta sección, necesita ocupa el segundo lugar, de acuerdo a su puntaje estadístico, en las colocaciones de "constitución" de La Nación.

Imagen 3: Concordancias "necesario" y "constitución" en El Mercurio

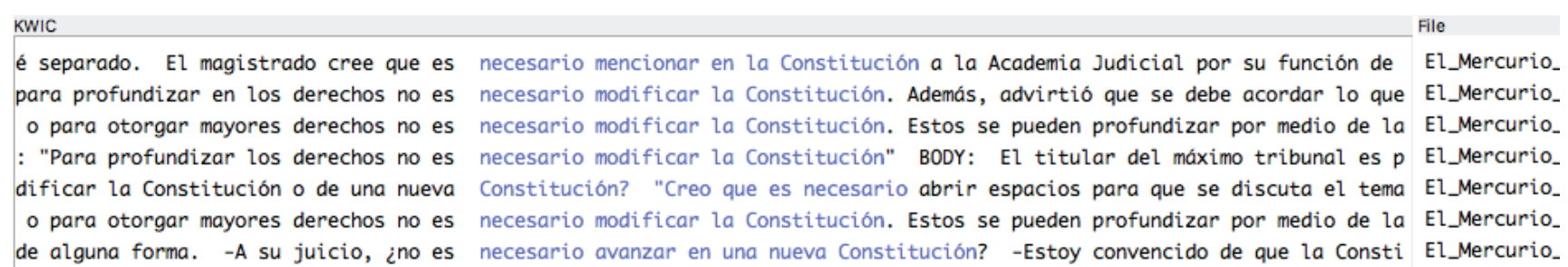

Imagen 4: Concordancias "necesita" y "constitución" en La Nación 
En el caso de La Nación, cuatro ocurrencias refieren a las cifras de las encuestas CADEM en torno a la aprobación de la necesidad de una nueva constitución. La otra es una pregunta en la entrevista al abogado constitucionalista Pablo Ruiz-Tagle, quien se muestra a favor de cambiar la constitución durante la entrevista.

En otras palabras, la colocación de necesita y constitución en La Nación refiere a datos de encuesta y a una opinión favorable al cambio de constitución. Llama la atención que El Mercurio no refiera estos datos de la encuesta Cadem, en la cual el porcentaje de encuestados que quiere cambiarla (por sobre el $70 \%$ ) es muy superior a la proporción de voces proclive a hacerlo que tienen cabida en el diario.

\subsubsection{Preocupa*}

Quisimos saber cuáles eran los focos de preocupación para El Mercurio en torno a la nueva constitución. La búsqueda de la expresión regular preocupa* permite buscar todas las palabras que comiencen con preocupa (preocupa, preocupar, preocupante, preocupación, etc.), lo que permite ampliar la posibilidad de tener colocaciones con frecuencia mayor o igual a cinco ocurrencias. Valga aclarar que en el caso de La Nación, no hay palabras léxicas que cumplan con dichos parámetros (frecuencia mínima de cinco ocurrencias).

En el análisis de las keywords habíamos señalado que para El Mercurio el derecho de propiedad era un concepto significativamente más presente en sus contenidos sobre la nueva constitución. Ahora es posible observar también que desde el punto de vista estadístico es la palabra léxica con mayor puntaje estadístico en tanto colocación de constitución.

\subsection{Algunas consideraciones sobre las herramientas utilizadas}

Como advertimos anteriormente, el uso de métodos de lingüística de corpus tiene limitaciones. La principal, que ya habíamos adelantado, tiene que ver con la pérdida del contexto que implica analizar los textos de

Tabla 6: Colocaciones "preocupa*” en El Mercurio

Colocaciones Preocupa*

\begin{tabular}{ccccc|} 
Frec. Total & Colocaciones Preocupa & \\
& Frec. Izquierda & Frec. Derecha & Puntaje Estadistico & Colocación \\
6 & 2 & 4 & 9.17193 & propiedad \\
5 & 2 & 3 & 6.91817 & sea \\
5 & 2 & 3 & 5.95112 & constituyente \\
7 & 2 & 5 & 5.49485 & proceso \\
5 & 3 & 2 & 4.77013 & constitución \\
12 & 4 & 8 & 4.70830 & del \\
22 & 6 & 16 & 4.69653 & a \\
33 & 18 & 15 & 4.57886 & el \\
10 & 5 & 5 & 4.49733 & un \\
7 & 4 & 3 & 4.07610 & una
\end{tabular}

Fuente: Elaboración propia 
manera agregada y no como unidades autocontenidas. Si bien esto permite encontrar patrones sujetos a significación estadística, la frecuencia del uso de palabras sigue siendo un factor fundamental.

Esto trae como contraparte una mayor dificultad para identificar una determinada posición ideológica-discursiva en la medida que utilice diversidad de palabras o sinónimos. Sabemos que El Mercurio utiliza muchas más palabras distintas que La Nación (ver Tabla 1), lo que otorga una mayor diversidad léxica. Esto implica que usa más sinónimos (por definición palabras distintas) para un mismo concepto o significado, lo que dificulta que alguno de estos conceptos figure en las herramientas de corpus si cada palabra tiene menos de cinco ocurrencias ${ }^{18}$. En la misma línea, al buscar colocaciones que están máximo cinco palabras a la izquierda o cinco palabras a la derecha de la palabra objetivo (que es la opción por defecto de AntConc y la más usada), se corre el riesgo de perder palabras que estén más lejos en oraciones más largas y elaboradas ${ }^{19}$.

Adicionalmente, sólo nos fue posible levantar un corpus similar al de El Mercurio con el diario

18 Para dar un ejemplo concreto: al buscar las colocaciones de idea el único adjetivo que aparece (teniendo una frecuencia mayor a cinco ocurrencias) es nueva y al mirar la tabla de concordancias son ocurrencias de nueva constitución. Sin embargo, al ver una por una todas las ocurrencias de idea, es posible encontrar los siguientes adjetivos: audaz, fantasiosa, cuestionada, mala, peor, peregrina y tonta. Cada una de ellas sólo aparece una vez. Todas refieren a la nueva constitución, por cierto.

19 Para ilustrar con otro ejemplo: en la frase "el ex ministro de la Segegob Álvaro Elizalde, afirmó que "la AC como mecanismo democrático para elaborar una nueva Constitución es un sentir ampliamente extendido entre los socialistas", ni AC (asamblea constituyente) ni socialistas serían consideradas como colocaciones de constitución al estar ocho palabras a la izquierda y ocho a la derecha respectivamente, siendo cinco palabras el criterio de corte.
La Nación. Para un próximo estudio de este tipo sería de gran provecho levantar bases similares en la mayor cantidad de diarios posibles para ampliar el parámetro de comparación y poder ver efectivamente qué tanto se diferencia El Mercurio del resto del universo de prensa escrita en Chile, aun considerando la alta concentración en lo que refiere a la propiedad de los medios.

Habiendo dicho todo lo anterior, creemos que este estudio debe a futuro complementarse con un análisis de discurso cualitativo, el cual sea capaz de dar cuenta de las distintas estrategias discursivas utilizadas por los medios escritos chilenos para referir el proceso constituyente. En la medida que se trata de cubrir un proceso esencialmente deliberativo, resulta crucial examinar de qué manera la prensa se articula en torno a él: si acaso toma partido y de qué manera lo hace (si es, por ejemplo, con argumentos razonables o con falacias), si hay un interés por representar fielmente las posiciones o si, acaso, hay un discurso ideológicamente dirigido a defender una determinada posición y/o atacar otra.

\section{Conclusiones}

Si bien los estudios sobre medios de comunicación masiva y de opinión pública son numerosos, el contexto de un proceso constituyente exige hacerse preguntas particulares, casi inexploradas por la literatura comparada. Este trabajo ha intentado ser un primer acercamiento a este tema en América Latina, una región caracterizada por democracias imperfectas, en que la contribución de los medios de comunicación a la calidad de la democracia es constantemente puesta en duda. 
En el contexto del proceso constituyente chileno, y tomando en consideración los estándares normativos que se derivan de una concepción deliberativa/dualista de la democracia, surgen preguntas sobre el rol de los medios de comunicación masiva y su contribución a una discusión política de carácter excepcional. En efecto, como vimos, la discusión política en momentos constitucionales está sometida a estándares democráticos más exigentes, y la necesidad de deliberar en torno a cuestiones sustantivas y procedimentales supone un proceso de discusión abierto, robusto e inclusivo. El protagonismo que ha adquirido el gobierno, y que se ha visto reflejado en las discusiones y polémicas sobre el rol difusor de la SEGEGOB, o las atribuciones del Consejo de Observadores Ciudadanos, tienden a minimizar el rol que tienen ciertos actores privados en el modo de abordar esta discusión. Además, la estructura del mercado de los medios de comunicación, en especial, de la prensa escrita, observa patrones de concentración que han erosionado la protección de la dimensión objetiva del derecho a la libertad de expresión.

Por ello, hemos intentado, a través de las diversas secciones, realizar ciertas preguntas sobre el modo en que los medios de comunicación escrita impactan en el proceso constituyente. ¿Están los diarios de circulación nacional abordando la discusión sobre el proceso constituyente haciéndose cargo de la seriedad de las discusiones involucradas? ¿Cómo influye la estructura del mercado de los medios de comunicación masiva en la calidad de la discusión constituyente? ¿De qué modo el actuar de los diarios como El Mercurio está cumpliendo con los estándares que exige una concepción deliberativa/dualista de la democracia? Hasta el momento, las respuestas son tentativas, pero el análisis de discurso asistido por corpus nos ha permitido visibilizar ciertas prácticas que nos llevan a ser críticos al respecto.

Este último ejercicio nos permitió mostrar que El Mercurio no ha estado actuando como un filtro que permita reproducir aquello que está realmente pasando en la opinión pública, como lo muestran diversas encuestas que han visibilizado el apoyo ciudadano mayoritario a favor de una nueva constitución. Más allá de lo que este medio reproduce o aborda, como preocupaciones en torno al derecho de propiedad o mayoría de voces que consideran innecesario cambiar la constitución; es también importante compararlo con aquello que no aborda, con aquello que deja sin tematizar, como lo son las encuestas que entregan mayorías por sobre el $70 \%$ de aprobación a la idea de cambiar la constitución. La concepción deliberativa de la democracia exige tomar en consideración aquellas voces que hasta el momento han sido invisibilizadas, asumiendo que ello mejorará la calidad y la imparcialidad del resultado de la discusión. Pero, además, el modo en que este diario ha articulado ciertos temas, como la necesidad de una nueva constitución, o la importancia del derecho de propiedad, refieren al modo en que se intenta articular a la opinión pública en torno a consensos que supuestamente no debieran cuestionarse. Una concepción dualista de la democracia nos enseña que en momentos excepcionales son justamente estos consensos, que en momento de política ordinaria funcionan como el trasfondo compartido, pasan a ser el principal objeto de tematización.

Ricardo Hepp, presidente de la Asociación Nacional de Prensa y, al mismo tiempo, 
representante del lector en La Tercera (el encargado de recibir y gestionar las críticas a las opiniones y al contenido de un medio de comunicación) criticó la "incertidumbre" que acarrea el proceso constituyente, y señaló que la libertad de prensa debe defenderse firmemente, pues "en nuestro país se vive un ámbito muy extenso de diversidad editorial, que se puede constatar cuando se revisa la oferta de los quioscos" (El Mercurio, 3 de Mayo de 2015). Si ésta es la opinión sobre el proceso constituyente de quien está llamado a defender al lector en un contexto de alta concentración de la propiedad de los medios de comunicación, pero que además dirige al conglomerado que reúne a los miembros del duopolio de la prensa escrita, y del oligopolio de las radioemisoras, el escrutinio académico y ciudadano es imperativo. Aún quedan muchas preguntas por plantear y responder, y el proceso constituyente chileno es una interesante oportunidad de combinar perspectivas de la teoría política y de las ciencias sociales para estudiar el rol de los medios de comunicación masiva en este tipo de procesos.

\section{Bibliografía}

Ackerman, B. 1998. We the people: Foundations. Cambridge: Harvard University Press.

Ackerman, B. y Rosenkrantz, C. 1991. "Tres concepciones de la democracia constitucional". Fundamentos y alcances del control judicial de constitucionalidad. Santiago: Centro de Estudios Constitucionales.

Arriagada, A. y Navia, P. 2013. Intermedios: Medios de comunicación y democracia en Chile. Santiago: Ediciones UDP.

Arriagada, A., Scherman, A. y Valenzuela, S. 2010. “¿Hacia una nueva ciudadanía multifuncional? Uso de medios digitales, redes sociales online y participación política". IV Congreso Latinoamericano de Opinión Pública de WAPOR. Belo Horizonte, Brasil.

Baker, P. 2007. Using corpora in discourse analysis. London: Continuum.

Baker, P. et al. 2011. "¿Una sinergia metodológica útil? Combinar análisis crítico del discurso y lingüística de corpus para examinar los discursos de los refugiados y solicitantes de asilo en la prensa británica". Discurso \& Sociedad, 4 (4): 376-416.

Baker, P. y McEnery, T. 2005. A corpus-based approach to discourses of refugees and asylum seekers in UN and newspaper texts. Journal of Language and Politics, 4 (2): 197-226.

Comisión Inter-Americana de Derechos Humanos-Relatoría para la Libertad de Expresión (2010). Declaración conjunta del décimo aniversario: Diez desafíos claves para la libertad de expresión en la próxima década. e Internet.

2011. Declaración conjunta sobre libertad de expresión

2012. Declaración conjunta sobre delitos contra la libertad de expresión.
Commission on Freedom of the Press. 1948. A free and responsible press.

Contreras Vázquez, P. y Contreras, P. 2012. Libertad de expresión: Por qué cayó Chile en el ranking de Reporteros Sin Fronteras. Santiago: CIPER Chile.

Consejo Nacional de la Cultura y las Artes. 2011. Estudio sobre el comportamiento lector a nivel nacional.

Couso, J. 2011. "El mercado como obstáculo a la libertad de expresión: La concentración de la prensa escrita en Chile en la era democrática". Disponible en: http://www.plataformademocratica. org/Publicacoes/17796.pdf (consultado en marzo de 2016).

Derechos Digitales. 2015. Ley de medios digitales es un atentado a libertad de expresión.

Ferreiro, J. M. 2014. "El Mercurio vs. La Asamblea Constituyente: Análisis de Discurso del uso del concepto 'Asamblea Constituyente' a lo largo de los años 2012 / 2013”. Disponible en: www.fundamental.cl (consultado en febrero de 2016).

Ferreiro, J. M. y Wodak, R. 2014. "Análisis Crítico de Discurso desde el Enfoque Histórico: La construcción de identidad(es) latinoamericana(s) en la misión de Naciones Unidas en Haití (20042005)". Escucha de la escucha. Análisis e interpretación en la investigación cualitativa. Ed. Canales, M. Santiago: LOM. 189-230.

Fishkin, J. y Luskin, R. 2005. "Experimenting with a democratic ideal: Deliberative polling and public opinion". Acta Política, 40: 284.

Fishkin, J. 2011. "Deliberative democracy and constitutions". What should Constitutions do? Eds. Frankel, E., Miller, F y Paul, J. Cambridge: Cambridge University Press. 242-260.

Fiss, O. 1999. La ironía de la libertad de expresión. Barcelona: Gedisa. 
Freedom House. 2015. Freedom of the press.

Friedman, B. 2009. The will of the people: How public opinion has influenced the supreme court and shaped the meaning of the constitution. Farrar, Straus and Giroux.

Fuentes, C. y Joignant, A. 2015. La solución constitucional. Santiago: Catalonia.

Ghai, Y. y Galli, G. 2006. "Constitution Building Processes and Democratization". Democracy, Conflict and Human Security: Further Readings (Stockholm: IDEA).

Godoy, S. 2016. "Media Ownership and Concentration in Chile". Who Owns the World's Media. Ed. Eli M. Noam. Oxford: Oxford University Press. 641-673.

Gronemeyer, M. y Porath, W. 2013. "Los niveles de coincidencias temáticas en editoriales de cinco diarios chilenos de referencia en un contexto de concentración de la propiedad de los medios". Estudios sobre el Mensaje Periodístico 19 (1): 433-452.

Guðbjörg, H. 2012. "The Icelandic media coverage of the constitutional assembly election", Vefbirting 8 (2): 367-388.

Habermas, J. 2006. "Does Democracy Still Enjoy an Epistemic Dimension?". Communication Theory 16: 411-426.

Hallin, D. y Mancini, P. 2004. Comparing Media Systems: Three Models of Media and Politics. Cambridge: Cambridge University Press.

Hart, V. 2003. "Democratic Constitution Making", Special Report (United States Institute for Peace).

Heath, J. 2001. Communicative action and rational choice. Cambridge: MIT Press.

Hunston, S. 2006. Corpora in applied linguistics. Cambridge University Press.

Klein, C. y Sajó, A. 2012. "Constitution-Making: Process and Substance". The Oxford Handbook of Comparative Constitutional Law. Eds. Rosenfeld, M. y Sajó. A. Oxford: Oxford University Press. 419-441.

Mauersberger, C 2016. Advocacy Coalitions and Democratizing Media Reforms in Latin America: Whose voice gets on the air? London: Springer.

Mautner, G. 2009. "Corpora and Critical Discourse Analysis". Contemporary corpus linguistics. London-New York: Continuum. 32-46.

Mautner, G. 2015. "Checks and balances: how corpus linguistics can contribute to CDA". Methods of critical discourse Studies. Eds. R. Wodak y M. Meyer. Thousand Oaks, CA: Sage Publications. 154-179.

Mellado, C. y Lagos, C. 2013. "Redefining comparative analyses of media systems from the perspective of new democracies", Communication \& Society 26 (4):1-24.

Messner, M. y Watson, M. 2008. "The Source Cycle. How traditional media and weblogs use each other as sources". Journalism Studies 9 (3): 447-463.

Monbiot, G. 2014. "How the media shafted the people of Scotland", The Guardian, 16 de Septiembre de 2014.

Moscoso, C. 2014. "The Chilean student movement: between the criminalisation of the media and the institutionalisation of a new 'common sense'", paper presented at the conference Radicalism and Reform in Latin America, May 14th, University of London, Goldsmiths.

Neblo, M. 2005. "Thinking through democracy, between the theory and practice of deliberative politics". Acta Politica, International Journal of Political Science 40: 169-181.

Noam, E. 2016. Who Owns the World's Media. Oxford: Oxford University Press.

Orpin, D. 2005. "Corpus Linguistics and Critical Discourse Analysis Examining the ideology of sleaze". International Journal of Corpus Linguistics 10 (1): 37-61.

OSCE Office for Democratic Institutions 2012. Handbook On Media Monitoring for Election Observation Missions (OSCE).

Parkinson, J. y Mainsbridge, J. 2013. Deliberative Systems: Deliberative Democracy at the Large Scale. Cambrdige: Cambridge University Press.

Programa de las Naciones Unidas para el Desarrollo. 2014. Auditoría a la Democracia: Más y mejor democracia para un Chile inclusivo.

Reporters Without Borders. 2015. World Press Freedom Index. Ruggiero, T. 2000. "Uses and Gratifications Theory in the 21st Century". Mass Communication \& Society 3 (1): 3-37.

Sajó, A. 2011. Constitutional Sentiments. New Haven: Yale University Press.

Stubbs, M. 1995. Collocations and semantic profiles: On the cause of the trouble with quantitative studies. Functions of Language, 2(1), 23-55. http://doi.org/10.1075/fol.2.1.03stu

Scheufele, D. y Tewksbury D. 2007. "Framing, agenda setting, and priming: The evolution of three media effects models". Journal of Communication 57 (1): 9-20.

Tomlinson, H. 2014. "The New UK Model of Press Regulation", LSE Media Policy Brief 12.

Undurraga, T. 2016. "The media's role in Dilma Rousseff's Impeachment", paper presented at the conference "Beyond the Turmoil: Transformations and Challenges of Contemporary Brazil", May 17 th, University of Cambridge.

United Nations. 2014. UNDP Guidance Note on Constitutionmaking Support.

Universidad Diego Portales. 2010. Primer Estudio Nacional sobre Lectoría de Medios Escritos.

Vargova, M. 2005. "Democratic Deficits of a Dualist Deliberative Constitutionalism: Bruce Ackerman and Jürgen Habermas". Ratio luris 18 (3): 365-386.

Waldron, J. 1999. "Deliberation, Disagreement and Voting". Deliberative Democracy and Human Rights. Eds. Koh, H. y Slye, R. New Haven: Yale University Press. 210-226.

Walzer, M. 2006. Politics and Passion: Towards a More Egalitarian Liberalism. New Haven: Yale University Press.

Wodak, R. y Meyer, M. 2015. Methods of Critical Discourse Studies. London: Sage

Zamorano, P. 2012. 'Cierre de La Nación: una política pública comunicacional es irrenunciable', CIPER Chile, 27 de Septiembre de 2012 
$\underline{\underline{128}}$ 